\title{
Investigation of DC magnetron-sputtered TiO2 coatings: Effect of coating thickness, structure, and morphology on photocatalytic activity
}

Daviðsdóttir, Svava; Shabadi, Rajashekhara; Galca, Aurelian Catalin ; Hald Andersen, Inge ; Dirscherl, Kai; Ambat, Rajan

Published in:

Applied Surface Science

Link to article, DOI:

10.1016/j.apsusc.2014.06.047

Publication date:

2014

Link back to DTU Orbit

Citation (APA):

Davið̋sdóttir, S., Shabadi, R., Galca, A. C., Hald Andersen, I., Dirscherl, K., \& Ambat, R. (2014). Investigation of DC magnetron-sputtered TiO2 coatings: Effect of coating thickness, structure, and morphology on photocatalytic activity. Applied Surface Science, 313, 677-686. https://doi.org/10.1016/j.apsusc.2014.06.047

\section{General rights}

Copyright and moral rights for the publications made accessible in the public portal are retained by the authors and/or other copyright owners and it is a condition of accessing publications that users recognise and abide by the legal requirements associated with these rights.

- Users may download and print one copy of any publication from the public portal for the purpose of private study or research.

- You may not further distribute the material or use it for any profit-making activity or commercial gain

- You may freely distribute the URL identifying the publication in the public portal 


\section{Accepted Manuscript}

Title: Investigation of DC magnetron-sputtered $\mathrm{TiO} 2$ coatings: Effect of coating thickness, structure, and morphology on photocatalytic activity

Author: Svava Daviðsdóttir Rajashekhara Shabadi Aurelian Catalin Galca Inge Hald Andersen Kai Dirscherl Rajan Ambat

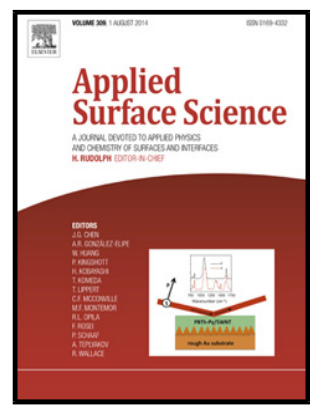

PII:

DOI:

Reference:

S0169-4332(14)01318-X

To appear in: $\quad$ APSUSC

Received date: $\quad$ 1-4-2014

Revised date: $\quad$ 6-6-2014

Accepted date: $\quad 8-6-2014$

Please cite this article as: S. Daviethsdóttir, R. Shabadi, A.C. Galca, I.H. Andersen, K. Dirscherl, R. Ambat, Investigation of DC magnetron-sputtered TiO2 coatings: Effect of coating thickness, structure, and morphology on photocatalytic activity, Applied Surface Science (2014), http://dx.doi.org/10.1016/j.apsusc.2014.06.047

This is a PDF file of an unedited manuscript that has been accepted for publication. As a service to our customers we are providing this early version of the manuscript. The manuscript will undergo copyediting, typesetting, and review of the resulting proof before it is published in its final form. Please note that during the production process errors may be discovered which could affect the content, and all legal disclaimers that apply to the journal pertain. 
Investigation of DC magnetron-sputtered $\mathrm{TiO} 2$ coatings: Effect of coating thickness, structure, and morphology on photocatalytic activity

Svava Daviðsdóttir ${ }^{*}$, Rajashekhara Shabadi ${ }^{b}$, Aurelian Catalin Galca ${ }^{c}$, Inge Hald Andersen ${ }^{d}$, Kai Dirscherl, and Rajan Ambat ${ }^{a}$,

*sdav@mek.dtu.dk

${ }^{a}$ Division of Materials and Surface and Engineering, Department of Mechanical Engineering, Technical University of Denmark, DK-2800 Kgs. Lyngby, Denmark

${ }^{\mathrm{b}}$ Denmark d Unité Matériaux et Transformations, C6, Université Lille, 59655 Villeneuve 'Ascq, France

${ }^{c}$ Laboratory of Multifunctional Materials and Structures, National Institute of Materials Physics, RO-077125, Măgurele-Bucharest, Romania

${ }^{\mathrm{d}}$ Danish Technological Institute, Tribology Centre, Teknologiparken, Building 18, Kongsvang All 29, DK-8000 Aarhus C, Denmark

${ }^{\mathrm{e}}$ Danish Fundamental Metrology, Matematiktorvet 307, DK-2800 Kgs. Lyngby, Denmark

Keywords: photocatalysis, $\mathrm{TiO}_{2}$, coatings, magnetron-sputtering, electrochemical impedance spectroscopy

\section{Abstract}

The photocatalytic performance of magnetron-sputtered titanium dioxide $\left(\mathrm{TiO}_{2}\right)$ coatings of different thickness in anatase crystalline structure deposited on aluminium 1050 alloy substrates was investigated using a combination of photo-electrochemistry, methylene blue decomposition, and microscopic and spectroscopic methods, such as high resolution scanning and transmission electron microscopy, atomic force microscopy and ellipsometry. The reaction resistance was measured by $\mathrm{AC}$ impedance, while photocurrent measurements were carried out using the zero resistance ammetry (ZRA) method. The results showed that the $\mathrm{TiO}_{2}$ grains grow in dipyramidal columns having a linear increase in surface area with increased coating thickness. The refractive index values indicate also an evolutionary growth. The refractive index values obtained for the thin coatings on aluminium substrate were well below the values reported for monocrystalline anatase. The photocatalytic performance 
increased with increased coating thickness, though more rapidly over a range of $100-500 \mathrm{~nm}$ thickness. The dielectric constant also increased linearly with coating thickness

\section{Introduction}

There is growing interest in titanium dioxide $\left(\mathrm{TiO}_{2}\right)$ in the anatase crystalline form due to the usefulness of its photocatalytic activity for number applications. These include solar energy conversion[1]'[2] electro-chromic devices[3], photocatalytic applications in air and water purification[4], self-cleaning and antimicrobial surfaces[5]. Therefore, significant research is being undertaken all over the world to understand the relationship between photocatalysis and morphology of $\mathrm{TiO}_{2}$ as a means to enhance its performance[6]', [7]', [8]', [9]

The high photocatalytic activity of anatase $\mathrm{TiO}_{2}$ is primarily due to the large band gap between the valence and conduction bands, resulting in high redox power[6]. Electromagnetic radiation with energy equal or higher than the band gap of $\mathrm{TiO}_{2}(3.2 \mathrm{eV})$ can excite electrons to the conduction band (CB), similar to other semiconducting materials. However, because of the large band gap, excitation of $\mathrm{TiO}_{2}$ produces high energy electrons and holes. The oxidative power of the holes is sufficient to decompose water molecules into hydroxyl radicals, while the high reductive power of the exited electrons will generate superoxide from oxygen. Both the hydroxyl radicals and the superoxide are useful in imparting photodecomposition of the dissolved organic material either by a reductive or oxidative process. The independent consumption of the generated electron-hole pair makes the material and its photocatalytic activity sustainable. 


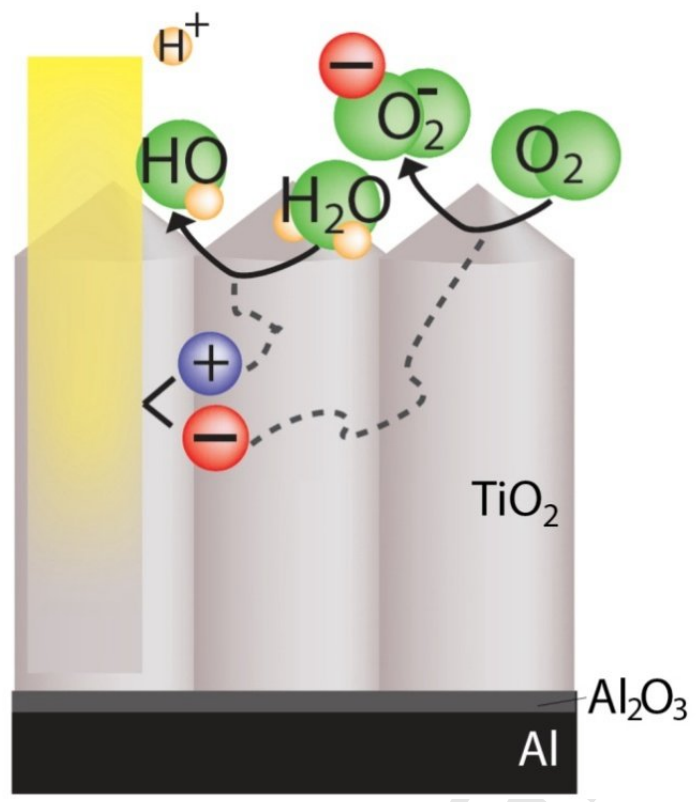

Figure 1. A schematic showing the $\mathrm{TiO}_{2}$ photocatalytic process. The UV-light absorbed will generate an electron-hole pair in the valence and conduction band respectively.

The photocatalytic activity of $\mathrm{TiO}_{2}$ is influenced by a number of parameters, including the morphology of the $\mathrm{TiO}_{2}$ particles or coatings, processing methods, crystallographic orientation, and the presence of dopants. It has been reported that the 004 face of $\mathrm{TiO}_{2}$, due to constrained alignment of the surface atoms[10], is more active than the 101 face $[11][12][10]$. A number of investigations have demonstrated that larger surface area increases the photocatalytic activity, and the photocatalytic activity was improved by addition of various dopants such as Cr, Mo, V, Mn, Fe, Co and Ni[13]'[14].

Most investigations in the literature related to photocatalysis of $\mathrm{TiO}_{2}$ focused on nanoparticles and coatings on glass substrates. A review by Debold[15] is a good summary of research done on $\mathrm{TiO}_{2}$ and shows the increased interest in this area as reflected by the increased number of publications, especially on single-crystalline $\mathrm{TiO}_{2}$. Moreover, this paper gives a brief introduction on metal/titanium dioxide interfaces and highlights its relevancy for further studies. It has been reported that the behaviour of $\mathrm{TiO}_{2}$ coatings on a metallic substrate is different from that of a non-metallic substrate due to the interplay between the conduction band of the substrate metal, band structure of the interfacing oxide, and band structure of 
$\mathrm{TiO}_{2}[16]$. Previous studies of $\mathrm{TiO}_{2}$ coatings on metallic substrates have demonstrated that the substrate can assist the charge separation and electron transfer, and increased coating thickness increases the activation depth and UV-absorption until a saturation depth of the coating is reached [17].

The change in coating thickness can influence the morphology and surface area of the top layer of the coating, which will have significant impact on the photocatalytic performance. The surface morphology of $\mathrm{TiO}_{2}$ also depends on the synthesis method. There are various techniques for synthesizing $\mathrm{TiO}_{2}$ coatings[3]. Among, and the most common methods are chemical solution deposition (CSD, Sol gel)[18]'[19] and physical vapour deposition (PVD)[20]'[21]. PVD is known to produce compact coatings with good adhesion to the substrate and the processing parameters, such as temperature and pressure, are controlled precisely and hence provide good reproducibility.

When a coating is deposited by vacuum techniques such as PVD, the size of the crystallites can increases with increased coating thickness due to the evolutionary nature of the growth[22]. In larger crystallites, the lifetime of the electron/hole is also lengthened as the pair migrates a greater distance in large crystallites than in smaller crystallites[23]. Greater electron-hole recombination distance increases the photocurrent, allowing more photocatalytic decompositions to take place.

The investigation reported in this paper focuses on the magnetron-sputtered $\mathrm{TiO}_{2}$ coatings of different thicknesses on an aluminium alloy (AA1050) substrate. Microstructural and surface morphological investigations were performed by atomic force microscopy (AFM), scanning electron microscopy (SEM), transmission electron microscopy (TEM), x-ray diffraction (XRD), and glow discharge optical emission spectroscopy (GDOES). The photocatalytic activity was determined by measuring:: (i) the reaction resistance under UV illumination based on impedance measurements, (ii) photocurrent upon UV illumination using zero 
resistance ammetry (ZRA), and (iii) the photocatalytic decomposition of methylene blue on $\mathrm{TiO}_{2}$ surfaces using UV light.

\section{Material and methods}

Substrate preparation: The substrate material used for the present investigation was AA1050 aluminium. AA1050 has a chemical composition (in \%) of $\mathrm{Cu}(0-0.05), \mathrm{Mg}(0-0.05), \mathrm{Si}(0-$ $0.25), \mathrm{Fe}(0-0.4), \mathrm{Mn}(0-0.05), \mathrm{Zn}(0-0.07), \mathrm{Ti}(0-0.07)$ and $\mathrm{Al}$ (balance). All the coated specimens were of the size $5 \mathrm{~cm} \times 5 \mathrm{~cm}$. The surface was polished to 1 micron surface finish by using a buffing machine (Polette 6NE from KE MOTOR A/S).

TiO $O_{2}$ coating Synthesis: The $\mathrm{TiO}_{2}$ coating on aluminium substrates was carried out by pulsed DC magnetron sputtering using an industrial CemeCon CC800/9 SinOx coating unit. The sputtering chamber was equipped with four magnetrons, each mounted with a $500 \mathrm{~mm} x$ $88 \mathrm{~mm}$ Ti target (purity 99.5 wt.\%). A pulsed DC power of $2 \mathrm{~kW}$ was applied to each magnetron, where the cathodes are running in dual magnetron sputtering mode at a frequency of $50 \mathrm{~Hz}$. The depositions were carried out in an argon/oxygen atmosphere at a total pressure of about $400 \mathrm{mPa}$. The $\mathrm{Ar} / \mathrm{O}_{2}$ gas flow ratio was $350 \mathrm{sccm} / 150 \mathrm{sccm}$, resulting in stoichiometric $\mathrm{TiO}_{2}$ coatings. The deposition temperature was approximately $150{ }^{\circ} \mathrm{C}$, and it was controlled by a resistive heater. The substrate was at floating potential where the self-bias was between $-6 \mathrm{~V}$ and $-9 \mathrm{~V}$. The deposition rate was $2.4 \mathrm{~nm} / \mathrm{min}$. The $\mathrm{TiO}_{2}$ coatings used for the present investigation were approximately $100 \mathrm{~nm}, 500 \mathrm{~nm}$, and $2 \mu \mathrm{m}$ thick.

Microstructural characterisation: Surface morphology and microstructural characterization of the coatings were carried out using FEG-SEM (SEM Quanta 200f). A Tecnai T-20 machine operating at $200 \mathrm{kV}$ was used to study the FIB cuts from the depths of the coating thickness.

The surface topography was studied using AFM in tapping mode (Dimension3100 Metrology). Chemical depth profiling of the coating was carried out using GDOES (RF GDOES GD profiler 2).

$X$-Ray diffraction: Phase analysis of the coating was examined with X-ray diffractometer (XRD) (D8 Discover). The measurement was carried out in grazing incident mode with an incident angle of $0.7^{\circ}$. 
Refractive index and high-frequency dielectrical constant: Optical measurements were performed with a Woollam Variable Angle Spectroscopic Ellipsometer, equipped with a high pressure Xenon discharge lamp incorporated in an HS-190 monochromator. Measurements were done in the IR-Vis-UV region of the spectrum at photon energies between $0.7(\sim 1771$ $\mathrm{nm})$ and $6.2 \mathrm{eV}(248 \mathrm{~nm})$, step of $0.01 \mathrm{eV}$, and at 45,60 and $75^{\circ}$ angles of incidence.

Tests using methylene blue decomposition: Decomposition of methylene blue by photocatalytic $\mathrm{TiO}_{2}$ surface was used for measuring the photocatalytic activity (redox indicator) of the surface according to the DIN standard 52980 entitled "Photocatalytic activity of surfaces -Determination of photocatalytic activity by degradation of methylene blue"[24]. The experiment was conducted using a flow cell in which the solution was exposed to $\mathrm{TiO}_{2}$ surface (area of $11 \mathrm{~cm}^{2}$ ) under UV light (with intensity of $2.9 \mathrm{~mW}$ for photon energy of 3.2 $\mathrm{eV}$, or $0.26 \mathrm{~mW} / \mathrm{cm}^{2}$ ), and the reacted solution was analysed for a decrease in methylene blue concentration using a UV spectrophotometer. A reference experiment was carried out just with aluminium substrate in order to determine the amount of methylene blue decomposed just by the UV light without $\mathrm{TiO}_{2}$ surface. Prior to the testing, all the samples were pre-soaked in the MB solution for 2 hours and the MB solution was then exchanged for fresh solution before testing.

Photo-electrochemical testing: Electrochemical measurements were used to understand the photocatalytic behaviour of $\mathrm{TiO}_{2}$ surface with and without UV light exposure. A standard three electrode electrochemical cell set up was used for these measurements. The electrochemical cell consisted of a quartz window and the specimen was loaded on the other side of the cell facing the quartz window. The specimen was pressed against an O-ring exposing a surface area of $9.6 \mathrm{~cm}^{2}$ to the solution. The quartz window was used to expose the specimen to the UV light by placing a UV source facing the quartz window. The reference electrode used for the measurement was $\mathrm{Hg} / \mathrm{Hg}_{2} \mathrm{SO}_{4} /$ saturated $\mathrm{K}_{2} \mathrm{SO}_{4}$ in order to avoid any chloride contamination to the solution. The counter electrode used was platinum. The electrolyte used for all experiments was de-ionized water with analytic grade $0.1 \mathrm{M} \mathrm{NaNO}_{3}$ for increasing the conductivity of the solution. The volume of the electrolyte used was $550 \mathrm{ml}$. The UV lamp used was a Philips home solarium and it was placed at $35 \mathrm{~cm}$ distance from sample. The (ZRA) technique was used for measuring the current response between the sample and a platinum electrode with and without UV. The increase in current under UV 
exposure represents the photocurrent due to photocatalysis. The potentiostat used for the experiments was Gill AC BI-STAT.

Electrochemical impedance measurements: Electrochemical impedance measurements were used to analyse the charge-transfer characteristics of the $\mathrm{TiO}_{2}$ coated sample across the coating. The transport of charge between the coating and substrate depends on the activation depth of the anatase coating, and any interface oxide layer present on the substrate surface. The impedance measurements were performed from $1 \mathrm{~Hz}$ to $1000 \mathrm{~Hz}$ with potentials ranging from -0.4 to +0.74 . The potentiostat used for the experiments was VSP from Bio Logic.

\section{Results and Discussion}

\subsection{Effect of coating thickness on anatase crystallite size and interface microstructure}

\subsubsection{Glow discharge optical emission spectroscopy}

Figure 2 shows the chemical depth profile of the $\mathrm{TiO}_{2}$ coating of different thicknesses on aluminium 1050 substrate prepared by pulsed DC magnetron sputtering. The deposition rate was $2.4 \mathrm{~nm} / \mathrm{min}$ and the thickness was assumed to increase linearly as a function of the deposition time. From the calibrated GDOES profile, the thicknesses were estimated to be around $100 \mathrm{~nm}, 500 \mathrm{~nm}$, and $2 \mu \mathrm{m}$. Compositional depth profiles of the Ti/O ratio indicated that the coating is stoichiometrically correct, with approximately 33 atomic $\%$ at $\mathrm{Ti}$ and 66 atomic $\%$ at $\mathrm{O}$.
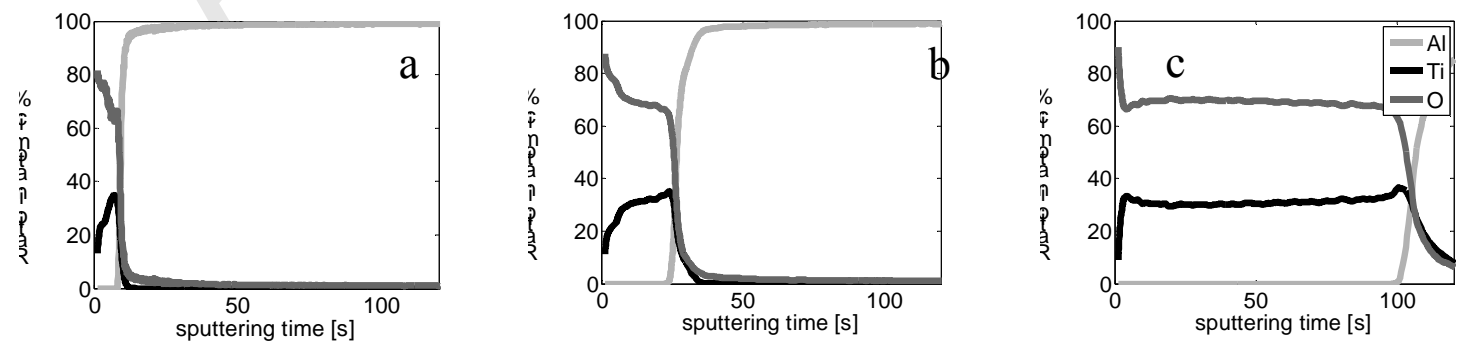

Figure 2. GDOES compositional depth profile of the $\mathrm{TiO}_{2}$ coating thickness in at $\%$ of a) $100 \mathrm{~nm}$, b) $500 \mathrm{~nm}$, c) $2 \mu \mathrm{m}$. 
All the profiles showed enhanced oxygen concentration near the surface, which is assumed to be due to trapped oxygen in the top layers of the rough (nano-scale) surface.

\subsubsection{Scanning electron microscopy}

Figure 3 a-c shows top view SEM images of the $\mathrm{TiO}_{2}$ coatings with increased thickness, from $100 \mathrm{~nm}, 500 \mathrm{~nm}$, and $2000 \mathrm{~nm}$, respectively, on aluminium. The SEM images clearly show that the $\mathrm{TiO}_{2}$ crystals grow in dipyramidal columns. As the coating thickness increases, the columns become wider with an increase in lateral column sizes.
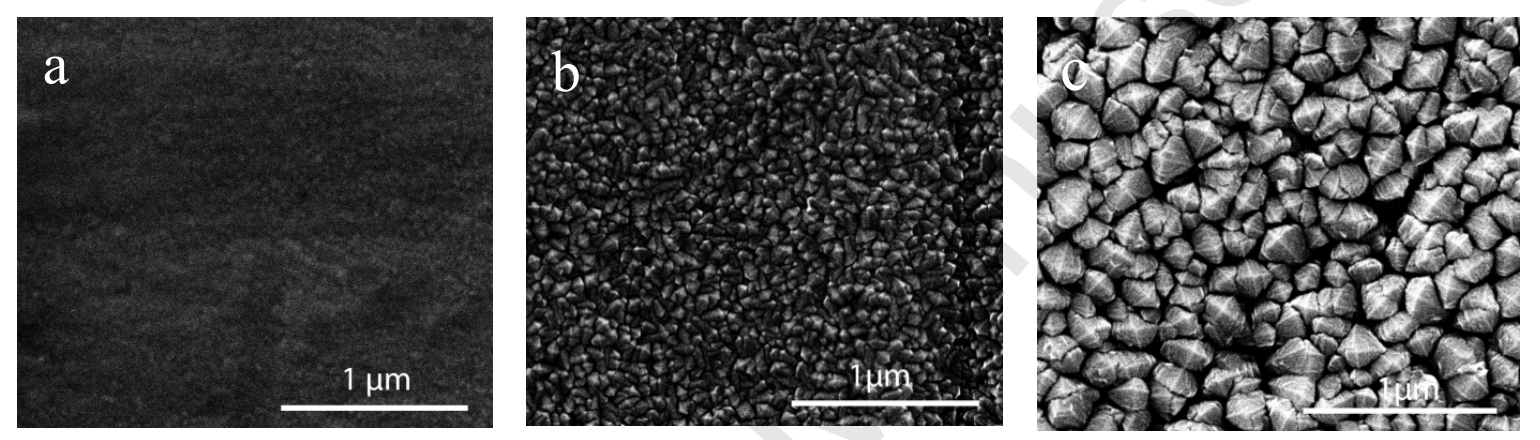

Figure 3. SEM images of the top view of $\mathrm{TiO}_{2}$ coating thickness of: a) $100 \mathrm{~nm}$, b) $500 \mathrm{~nm}$ and c) $2 \mu \mathrm{m}$.

\subsubsection{Atomic force microscopy}

A similar surface topography is observed from the 3D AFM images in Figure 4, which show an incremental increase in the columnar size, and increased roughness and surface area related to the coating thickness.
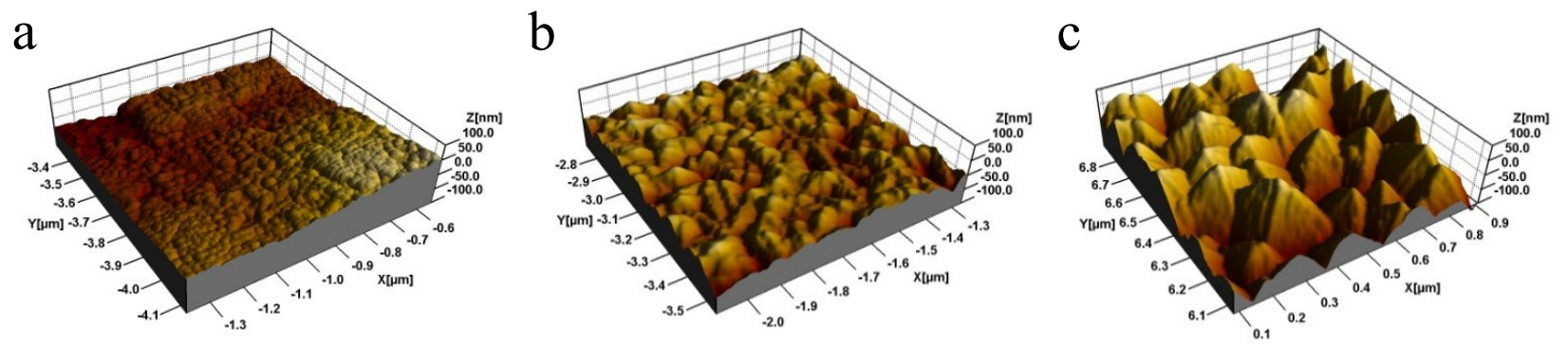

Figure 4. AFM images of the topography of $\mathrm{TiO}_{2}$ coatings with thickness of a) $100 \mathrm{~nm}$, b) $500 \mathrm{~nm}$ and c) 2 $\mu \mathrm{m}$. 
Quantitative measurements of the AFM images reveal that there is a linear relationship between the thicknesses of the coating and widening of the columns which define the in-plane cross-sectional area of the columns (Figure 5). As the width of the column increases, the surface area also increases. The plot in Figure $5 \mathrm{~b}$ shows that the surface area increases linearly with thickness of the coating due to increased roughness. The surface area ratio was calculated with the commercial software "Scanning Probe Image Processor SPIP" (Image Metrology A/S, Hoersholm, Denmark) according to the standard ISO/DIS 25178-2, where the percentage increase in the interfacial surface area relative to the projected area is calculated. The increased surface area is advantageous for photocatalytic activity as it provides more sites for the reactions to occur[6]'[25].

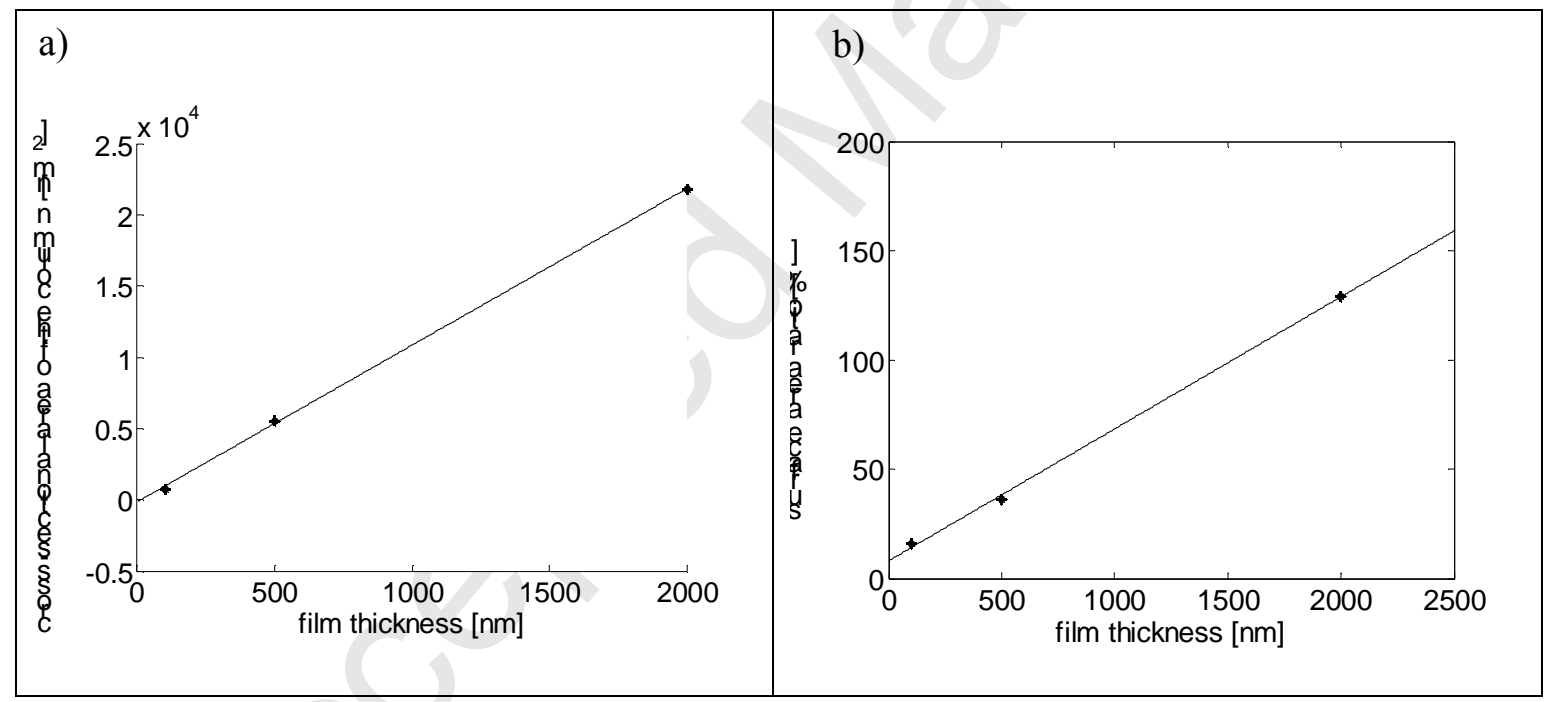

Figure 5: Sputter coated $\mathrm{TiO}_{2}$ coating: a) Correlation between coating thickness and column in-plane cross section area. b) Correlation between coating thickness and surface area ratio

\subsubsection{Transmission electron microscopy}

The TEM image presented in Figure 6 shows the cross-sectional profile of coatings of various thicknesses. The magnified image for the $100 \mathrm{~nm}$ thickness (Figure 6a) shows that approximately $4 \mathrm{~nm}$ of aluminium oxide layer is present. Furthermore, Figure $6 \mathrm{~b}$ shows that the coating texture consists of two different zones, labelled $\mathrm{C}$ and $\mathrm{D}$ in the figure. The formation of the zones is influenced by the processing parameters; the pressure is $4 \mathrm{mPa}$ and the ratio between the surface temperature and the melting point of the coating is below 0.3 . 
The coating morphologies observed for the different thicknesses are similar to those of the Thornton structure zone model[26]'[27]'[28]. Zone 1 (labelled C in Figure 6) consists of narrow crystals separated by voided boundary as is better visualised in Figure 6d. The top surface of the $100 \mathrm{~nm}$ coating seen in the AFM and SEM images are influenced by shape of initial nucleation. Zone T (labelled D) dominates after a thickness of approximately $100 \mathrm{~nm}$, where adatom diffusion largely overcomes the shape of the initial nucleation and the coating become denser. This is reflected in Figure 6d. As seen in all the pictures, the coating shows dipyramidal columnar growth originating from the interface to the surface.
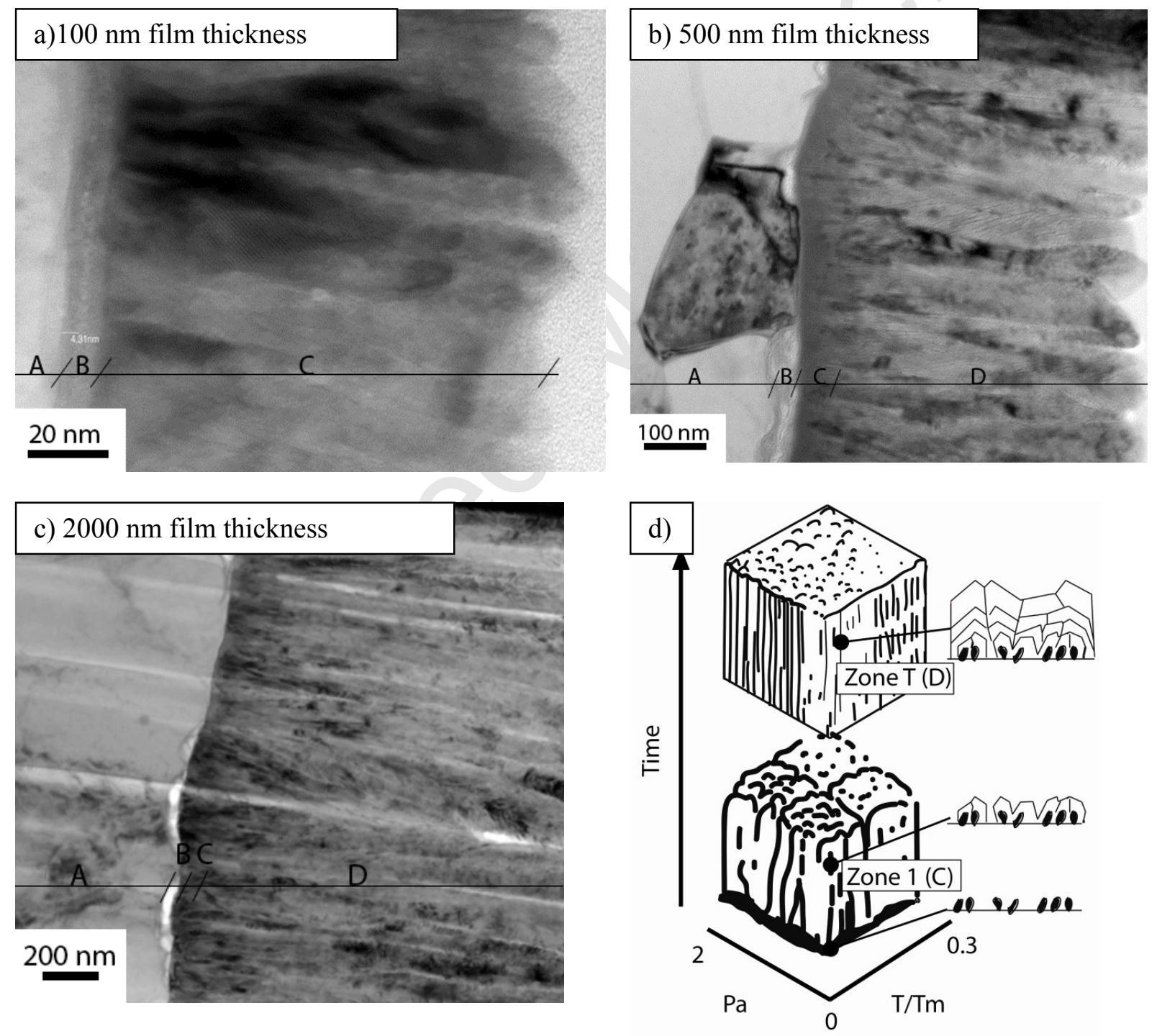

Figure 6. TEM cross-sectional images of $\mathrm{TiO}_{2}$ coatings of a) $100 \mathrm{~nm} \mathrm{TiO}$ b) $500 \mathrm{~nm} \mathrm{TiO}_{2}$ and c) $2 \mu \mathrm{m}$ where different regions are represented: (A) Aluminium, (B) Aluminium oxide, (C) $\mathrm{TiO}_{2}$ coating of zone 1, (D) $\mathrm{TiO}_{2}$ coating of zone T. Panel d) is an explanation of the growth of $\mathrm{TiO}_{2}$ coatings and is modified from figures in a publication from Thornton, J. A [28] and Rodriguez-Navarro, A. B [29]. The T/Tm is the ratio between temperature of the substrate and the melting point of titanium dioxide. The $\mathrm{Pa}$ is the pressure of the inert gas in Pascal. Time is the synthesis time,. 


\subsubsection{Grazing angle X-ray diffraction}

Figure 7 shows the results from the XRD measurement with grazing incident angle of 0.7 where penetration depth for $80 \%$ of the beam from the top layer is $350 \mathrm{~nm}$. The diffraction pattern of the peaks corresponds to anatase phase (red lines) and aluminium peaks (blue lines).

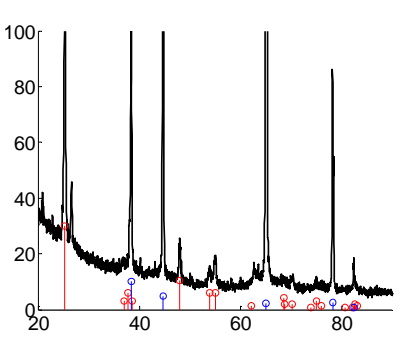

a)

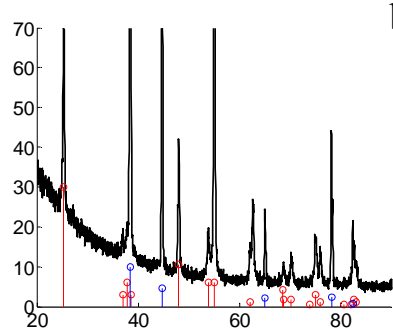

b)

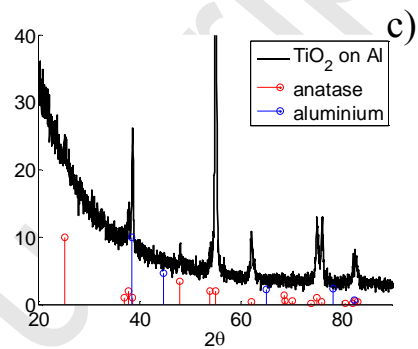

Figure 7. X-ray diffractogram of the $\mathrm{TiO}_{2}$ coatings, together with peaks corresponding to anatase powder pattern (pdf file: 21-1272) and aluminium (pdf file: 04-0787) on TiO2 film of a) $100 \mathrm{~nm}$, b) $500 \mathrm{~nm}$ and c) $2 \mu \mathrm{m}$

\subsubsection{Ellipsometry}

Ellipsometry was used to determine the dielectric constant of the coatings, which is an important property for photocatalytic performance as it demonstrates the ability of a coating to develop charge dipoles. A higher dielectric constant reflects more displacement of the electron and the hole, which enhances the lifetime of the electron-hole separation. In order to get a reliable and qualitative understanding of the dielectric constant and the refractive index, the simplest optical model was used, which consists of a metallic substrate, a Cauchy layer[30] $n(\lambda)=A+\frac{B}{\lambda^{2}}$, and an intermix layer between them. The fitting procedure was performed in the $0.7-3 \mathrm{eV}$ spectral range, in which it is assumed that the $\mathrm{TiO}_{2}$ layer is fully transparent. An intermix layer $(40 \mathrm{~nm})$ was required due to the imperfect surface optical quality of the bare substrate. The high frequency dielectric function can easily be determined, $\varepsilon_{\infty} \cong A$.

For confirmation of the optical properties, a multi-layered optical model was employed. Starting from a single Cauchy layer model (data) obtained for the $100 \mathrm{~nm}$ thick $\mathrm{TiO}_{2}$, one and 
two extra Cauchy layers were added for the $500 \mathrm{~nm}$ coating and $2 \mu \mathrm{m}$ thick coating, respectively. The refractive index and dielectric function increased linearly as the thickness increased (Figure 8) The refractive index at $552 \mathrm{~nm}$ is $1.91,2.10$, and 2.66 for $100 \mathrm{~nm}, 500 \mathrm{~nm}$, and $2 \mu \mathrm{m} \mathrm{TiO}_{2}$ coating respectively. For comparison, the refractive index values of bulk anatase are represented by the blue line in Figure $8 \mathrm{~A}[31]$.
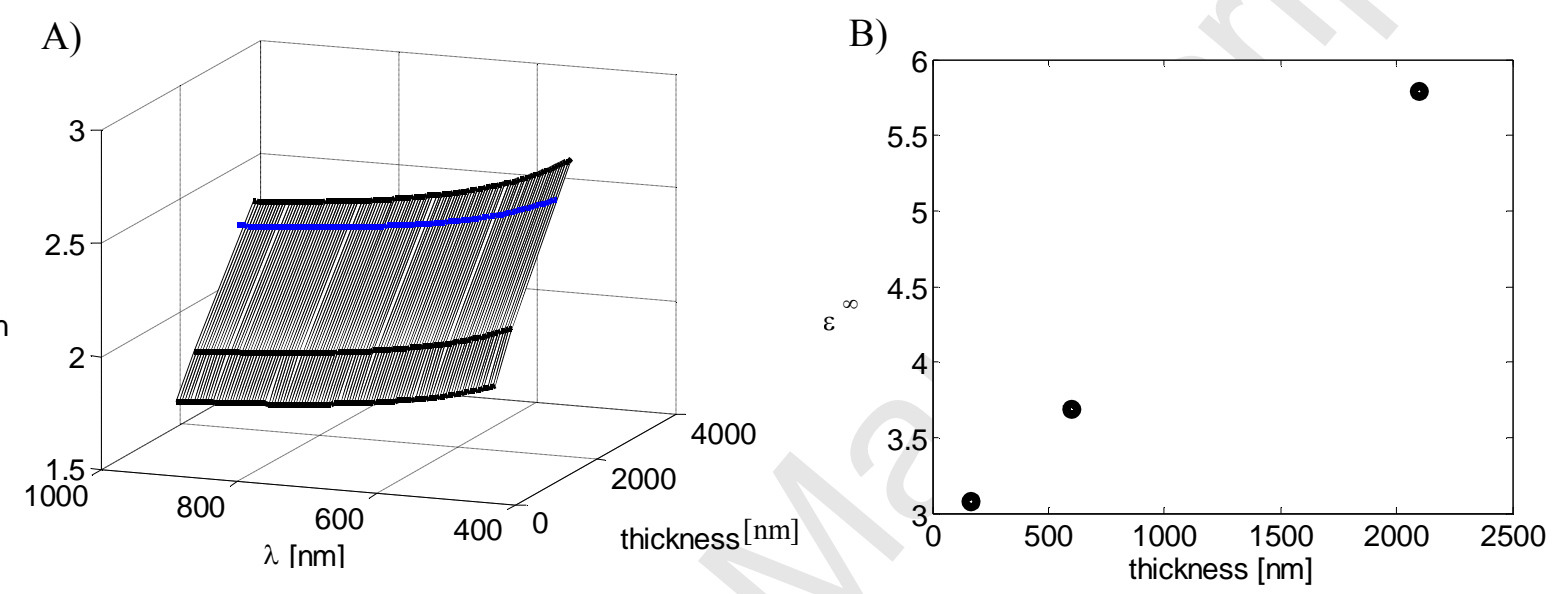

Figure 8. A) Refractive index of $\mathrm{TiO}_{2}$ coating as a function of its thickness. B) The high-frequency dielectric constant as a function of coating thickness.

The refractive index is linearly influenced by the density of the coating[32]'[33], which increases with coating thickness.. When the coating becomes thicker, it becomes denser and the spacing between the atoms is reduced. The increase in density with thickness of the coating can be explained as being due to the ' $\mathrm{V}$ ' shaped columnar growth of the thin coatings.[34]'[29] This can be visualised in Figure 6d. With increased thickness, the grains grow larger and the coating becomes denser. The dependency between the increased refractive index and increased grain size has been reported in the literature [35]

\subsection{Photocatalytic activity as a function of thickness}

\subsubsection{Decomposition of methylene blue as a function of time}

Figure 9 shows the decomposition of the methylene blue by $\mathrm{TiO}_{2}$ coatings with UVillumination measured over a period of three hours. The results represent the net decomposition of the indicator with UV light and were obtained by subtracting the level of decomposition caused by the absorption of the indictor into $\mathrm{TiO}_{2}$ film by measuring in the absence of the UV-light. 


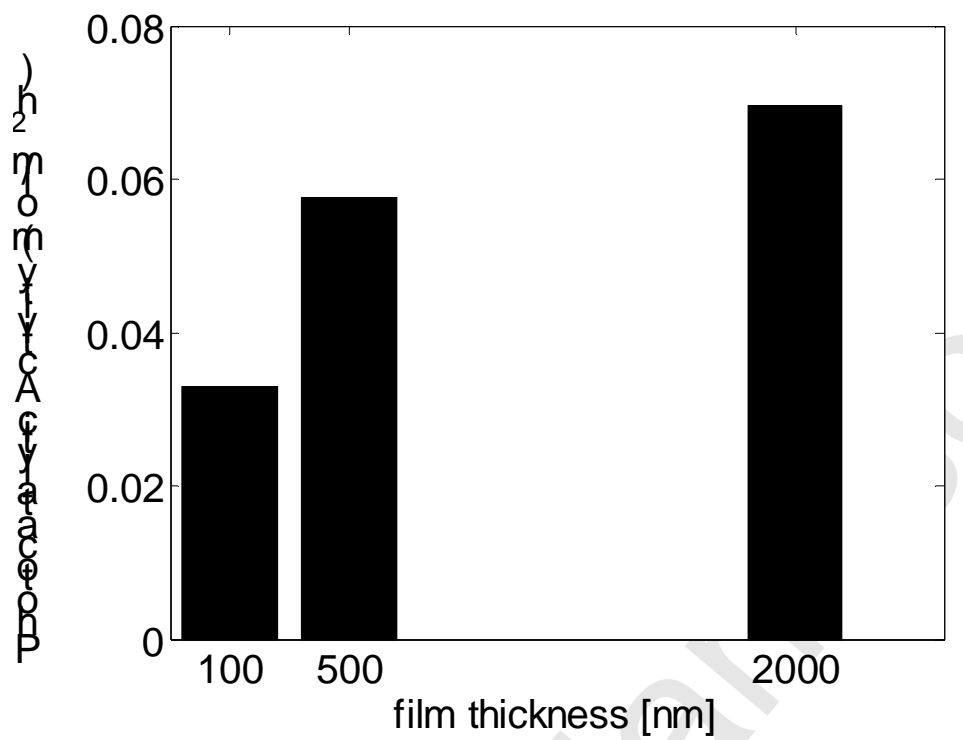

Figure 9. Photocatalytic activity of the $\mathrm{TiO}_{2}$ surface measured using the methylene blue decomposition method. It is clear from the results that the thicker the coating, the higher the photocatalytic activity, although the activity increases more between 100 to $500 \mathrm{~nm}$ compared to between 500 and $2000 \mathrm{~nm}$. Increasing the coating thickness from 100 to $500 \mathrm{~nm}$ roughly doubles the activity; while the activity increases only $20 \%$ from $500 \mathrm{~nm}$ to $2 \mu \mathrm{m}$. Increased photocatalytic activity with increased coating thickness using the methylene blue decomposition method was previously reported by Jung. et al[36] and Heikkilä et al[37]. The study carried out by Jung et al. used $\mathrm{TiO}_{2}$ coating made on quartz glass and alumina balls by chemical vapor deposition (CVD). The photocatalytic activity increased with coating thickness up to $5 \mu \mathrm{m}$ when the thickness was varied from $100 \mathrm{~nm}$ to $15 \mu \mathrm{m}$. The surface area increased with coating thickness, as evaluated from the $\mathrm{TiO}_{2}$ coatings on quartz substrate, until thickness of $2 \mu \mathrm{m}$ was obtained[36]. Moreover, the study by Heikkilä et al., which used $\mathrm{TiO}_{2}$ coating of 50 to $500 \mathrm{~nm}$ on a quartz substrate, showed an increase in photocatalytic activity upon increased coating thickness with saturation limit of $356 \mathrm{~nm}$. However, the surface area of the samples increased linearly with increased coating thickness[37]. The results from these studies 
indicate that the surface area partially influences the photocatalytic activity by providing more reaction sites on the surface for the photocatalytic reaction. However, the change in photocatalytic activity does not follow the same trend as the change in surface area upon increased $\mathrm{TiO}_{2}$ coating thickness, which strongly suggests that the surface area is not the only parameter influencing the photocatalytic activity.

\subsubsection{Photoelectrochemical measurements using the ZRA technique}

Photocurrent measurements were carried out using a standard three electrode chemical set up employing Zero Resistance Ammetry (ZRA) method. Platinum was used as the second electrode and the reference electrode was mercury sulfate. Figure 10 shows the measured current between the platinum and the sample, with and without UV illumination. When the sample was irradiated with UV light, higher negative current was generated, demonstrating the quantity of the electron-hole pairs formed. The negative current indicates that the positive current flows into the electrolyte and is consumed in the oxidation reaction while the electron is transferred to the platinum electrode. When the UV illumination was terminated, the current dropped quickly to the same level as before the illumination, which indicates that the original state was reached within a short interval of time. The first illumination with UV light showed a sudden surge in the current, followed by a decrease with exposure time. However, a surge in the current of similar magnitude was not observed for the subsequent activated peaks. This initial surge in current with coating thickness, increased in the order, $2000 \mathrm{~nm}>500 \mathrm{~nm}>$ $100 \mathrm{~nm}$. 


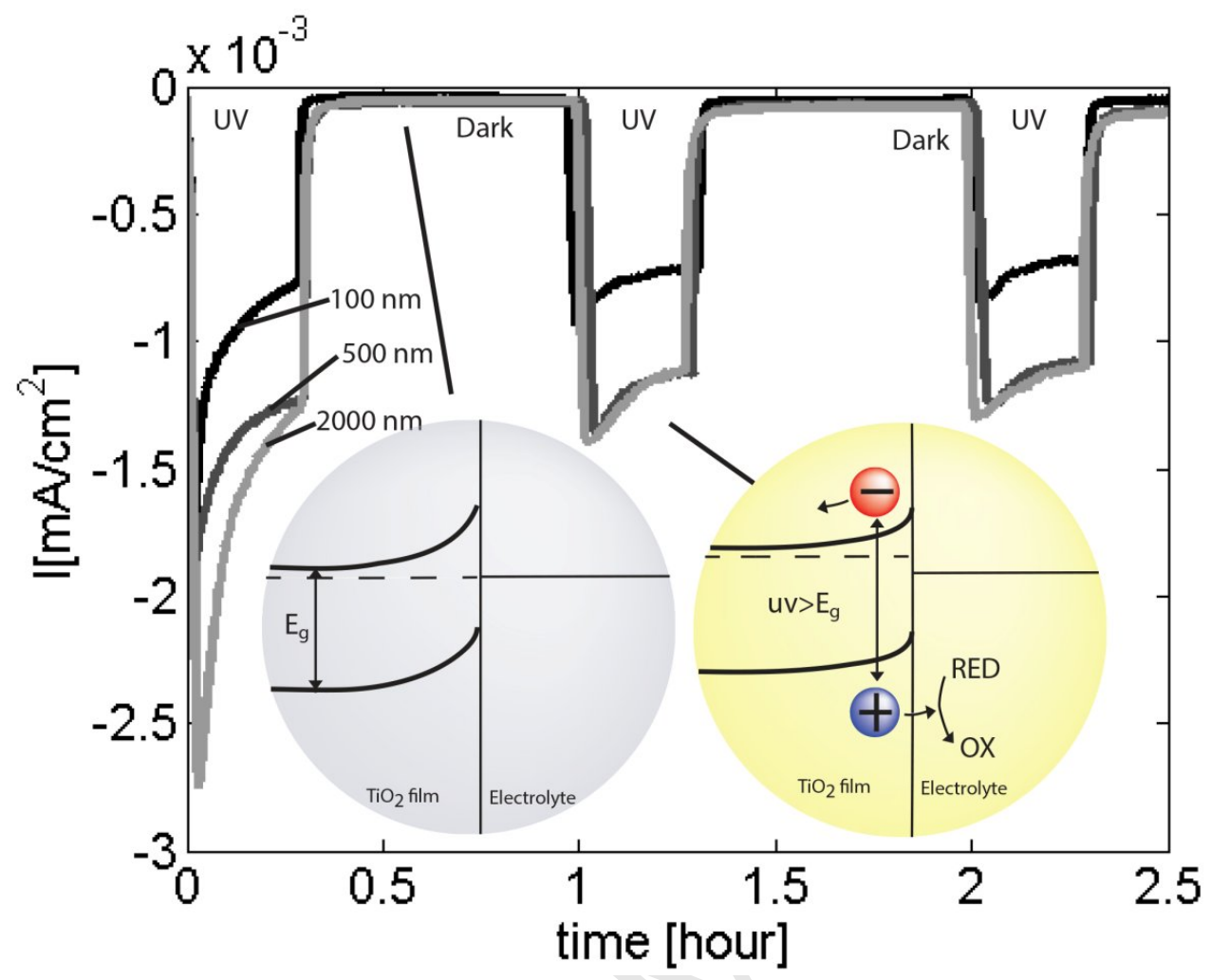

Figure 10. The current measurements of $\mathrm{TiO}_{2}$ coating on aluminium with time. The sample was activated three times with UV light for 15 min each time with 45 min break between the excitations.

Similarly, the magnitude of the plateau current generated by the UV illumination was significantly lower for the $100 \mathrm{~nm}$ coatings compared to the $500 \mathrm{~nm}$ and $2000 \mathrm{~nm}$ samples, while the difference was negligible between the $500 \mathrm{~nm}$ and 2 micron samples. Table 1 shows the total charge after the last illumination, which was obtained by integrating the area under the curve. The total charge remained the same for the 500 and $2000 \mathrm{~nm}$ samples, while the $100 \mathrm{~nm}$ sample showed less charge. The magnitude of the current and total charge corresponds to the efficiency of the photocatalytic process.

Table 1. The charging accruing in the $\mathrm{TiO}_{2}$ coating (the integral of the current/time plot, Figure 10).

\begin{tabular}{|c|c|c|}
\hline $100 \mathrm{~nm}$ & $500 \mathrm{~nm}$ & $2000 \mathrm{~nm}$ \\
\hline$-0.8 \mathrm{mC} / \mathrm{cm}^{2}$ & $-1.2 \mathrm{mC} / \cdot \mathrm{cm}^{2}$ & $-1.3 \mathrm{mC} / \cdot \mathrm{cm}^{2}$ \\
\hline
\end{tabular}




\subsubsection{Electrical properties of $\mathrm{TiO}_{2}$}

Impedance measurements were carried out to evaluate the electrical properties of $\mathrm{TiO}_{2}$, including the reaction resistance and capacitance behaviour with increased coating thickness on the aluminium substrate. The reaction resistance upon illumination is of special interest due to its connection with the consumption of electrons and holes on the surface of the titanium dioxide. When the reaction resistance is lower than the photo-generated resistance, holes are consumed faster, forming hydroxide radicals. The impedance measurements were taken at various potential values corresponding to different positions within the band gap of $\mathrm{TiO}_{2}$. The potential window used for the measurement was between $-0.4 \mathrm{~V}$ (just below the theoretical conduction band of $\mathrm{TiO}_{2}$ ) and $0.75 \mathrm{~V}$. The results are presented as a Nyquist plot in Figure 11, and the capacitance and the resistance can be extracted from the semicircles. The top and bottom panels represent sample without and with UV light, respectively. The entire impedance spectra consist of a semicircle, but the dimension and nature of the semicircle vary. The diameter of the semicircle is a measure of the reaction resistance. When the sample was excited with UV-light, the size of the semicircle decreased, indicating that the reaction resistance decreased. 


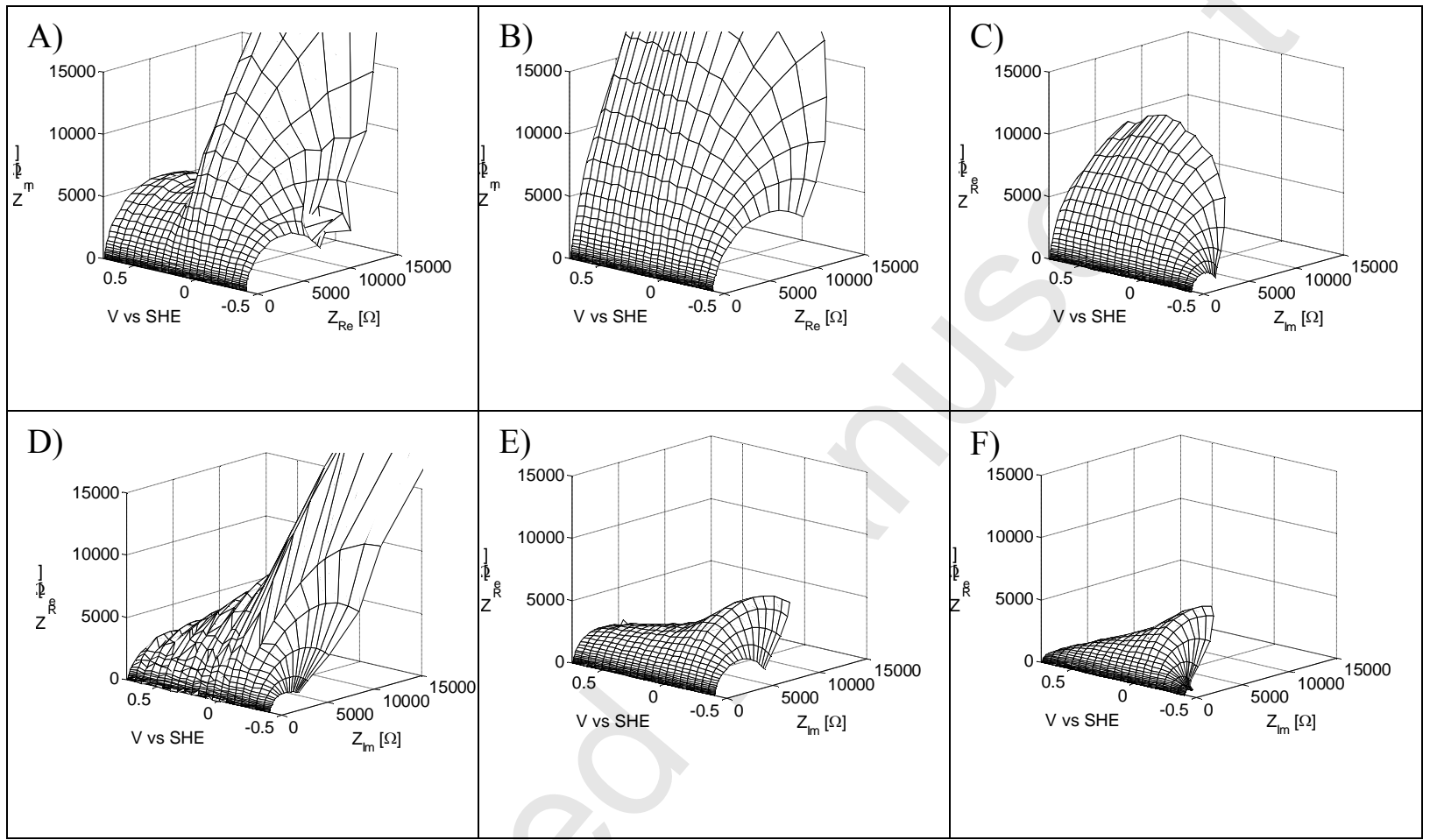

Figure 11. Nyquist plot of TiO2 on an aluminium surface in the dark, A) $100 \mathrm{~nm}, \mathrm{~B}) 500 \mathrm{~nm}$, and C) $2 \mu \mathrm{m}$ and during illumination, D) $100 \mathrm{~nm}$, E) $500 \mathrm{~nm}$, and F) $2 \mu \mathrm{m}$.

The impedance data was fitted to quantify the resistance and capacitance. The model used for the fitting is based on our previously reported method [16]. The Constant Phase Element (CPE) was used due to the non-uniformity of the titanium dioxide surface. When the sample was activated with UV light, the semicircle became smaller, indicating a lower reaction resistance of the coating. As the coating became thicker, the reaction resistance was reduced, thus facilitating the decomposition reactions. As can be seen in Figure 12, the reaction resistance with UV exposure decreased exponentially with increased thickness. The $100 \mathrm{~nm}$ coating had the highest reaction resistance and the lowest photocatalytic activity of the three samples. A decrease in the reaction resistance was observed for samples at a potential close to the theoretical potential of the $\mathrm{TiO}_{2}$ conduction band, which is about -0.45 for a solution of pH 5.5 used in the experiments. The reaction resistance increased as the potential went from - 
0.4 vs SHE, close to potential the conduction band of $\mathrm{TiO}_{2}$, until a maximum was reached between -0.2 and $0 \mathrm{~V}$ or close to the open circuit potential. After the maximum was reached, the reaction resistance decreased slowly as it approached the valence band of $\mathrm{TiO}_{2}$.

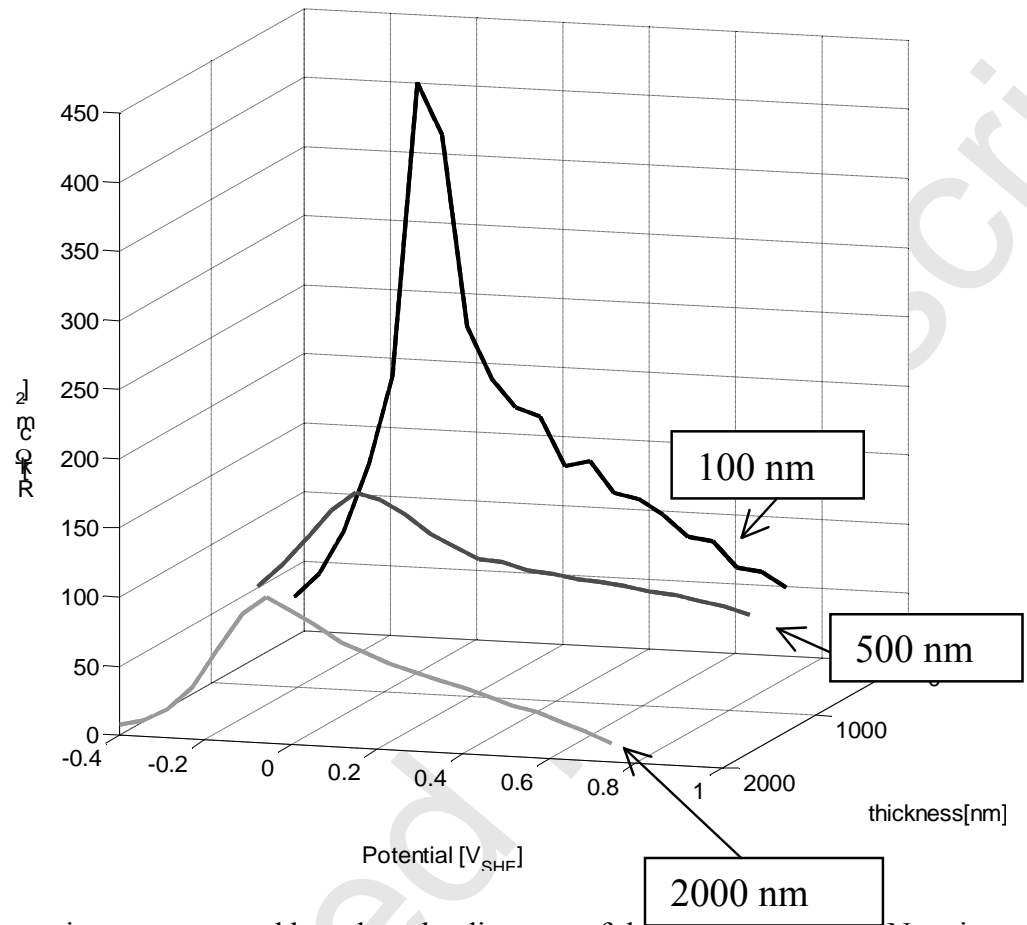

Figure 12. Reaction resistance extracted based on the diameter of the semicircle in the Nyquist measurements. The reaction resistance increased mostly between the thinner coatings, and as the coating became thicker, there was only a slight change in the reaction resistance. Lower reaction resistance indicates easier consumption of the holes on the surface, resulting in the formation of hydroxyl radicals that cause the decomposition. The open circuit potential for the samples during UV illumination was $-0.20 \mathrm{~V},-0.17 \mathrm{~V}$, and $-0.16 \mathrm{~V}$ for the coatings of $100 \mathrm{~nm}, 500 \mathrm{~nm}$, and $2 \mu \mathrm{m}$, respectively. The reaction resistance values are in agreement with the methylene blue test and the zero resistance ammeter measurements with respect to the photocatalytic behaviour. Thicker coatings generate more photocurrent with less reaction resistance, indicating that more electrons and/or holes are produced. There are several reasons for the increased photocatalytic activity with coating thickness. The increased thickness results in more surface area, with more sites for performing the reaction. Moreover as the crystals get 
larger, the hole/electron recombination is reduced[23]. Furthermore, increased thickness results in increased UV absorption until saturation depths have been reached. The saturation depth for PVD-synthesized $\mathrm{TiO}_{2}$ coatings used in the present investigation has been reported to be around $1 \mu \mathrm{m}[17]$. Figure 13 shows the change in capacitance of the coatings with and without UV light exposure. The capacitance of the $\mathrm{TiO}_{2}$ coatings increased linearly with increased coating thickness in the absence of UV light, which indicates that the potential drops across the space charge region rather than across the entire coating thickness as is characteristic in semiconductors. The space charge region is close to the surface where the $\mathrm{CB}$ and VB bend upward to adjust to the redox potential of the electrolyte. The relationship between the capacitance, surface roughness, dielectric constant and space charge distance can be seen in equation (5).

$$
\mathrm{C}=\frac{a \varepsilon_{\mathrm{g}} \mathrm{A}}{\mathrm{L}}
$$

Where $\mathrm{C}$ is the space charge capacitance, $\varepsilon$ is the relative permittivity (dielectric constant) and $\varepsilon_{0}$ is the permittivity of the free space, $\mathrm{A}$ is the total surface area (calculated from the surface area ratio acquired from AFM), and L is the depth of the space charge region for a semiconductor[38]. The surface area of the sample and its dielectric constant increased linearly with increased coating thickness, following the same trend as the capacitance. The depth of the space charge region was calculated by rearranging equation 5 . The space charge layer of the samples as a function of thickness can be seen in Figure 14, in the dark (A) and under illumination (B). The layer was approximately $2 \mathrm{~nm}$ for all samples, with increased slope for higher potential. The typical range of space charge thickness of thin coatings in semiconductors is between $1-10^{3} \mathrm{~nm}[39]$. Moreover, it was reported by Tiejun and al. that the best superficial space charge layer thickness of $\mathrm{TiO}_{2}$ was about $2 \mathrm{~nm}$ and the thickness of the layer decreased with increased amount of ion doping [40]. 
When the $\mathrm{TiO}_{2}$ coating is illuminated with UV light, small changes in the capacitance are observed. In the case of the $2 \mu \mathrm{m}$ thick coating, the capacitance decreased during exposure to UV light. The UV light caused the coating to become more conducting, allowing the potential to drop further across the coating thickness, which can be visualised by looking at the increased space charge depth. For the $100 \mathrm{~nm}$ thick coating, the capacitance showed an increase during exposure to UV light unlike the other coatings. This might be due to the effect of the substrate oxide coating on the electrical properties of $\mathrm{TiO}_{2}$.
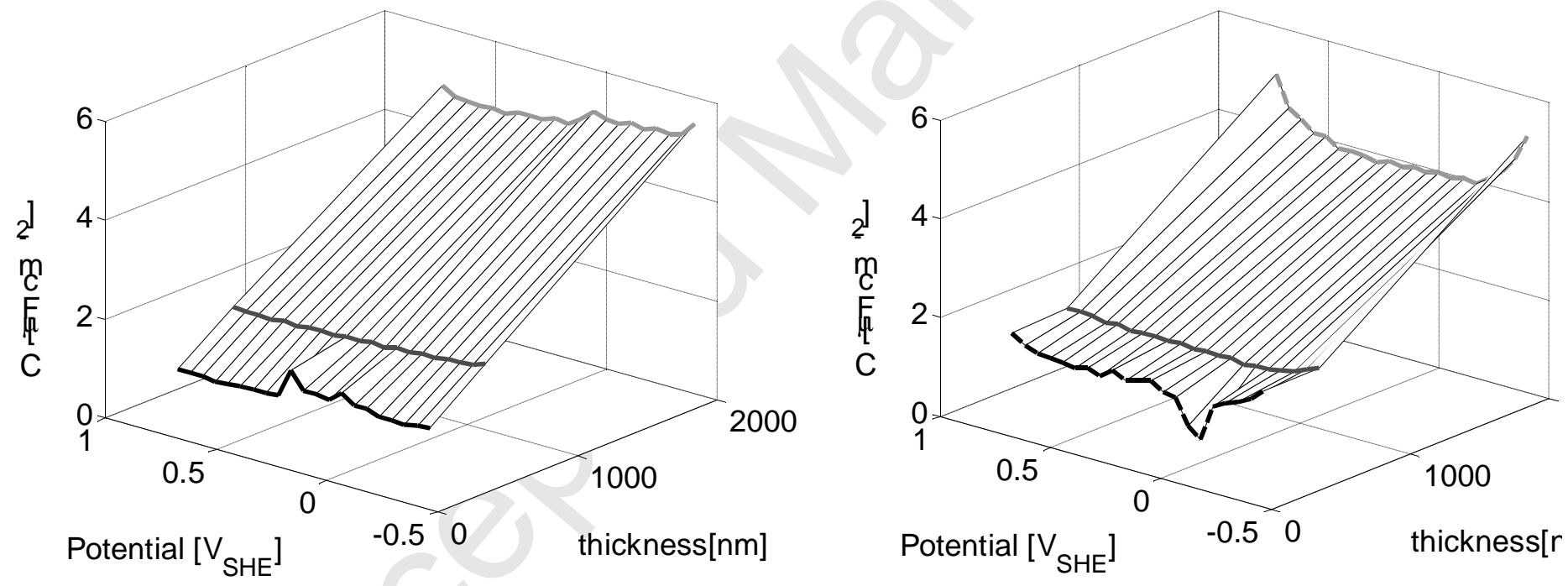

Figure 13. Capacitance of the $\mathrm{TiO}_{2}$ coatings: A) in dark, and $\mathrm{B}$ ) under $\mathrm{UV}$ illumination
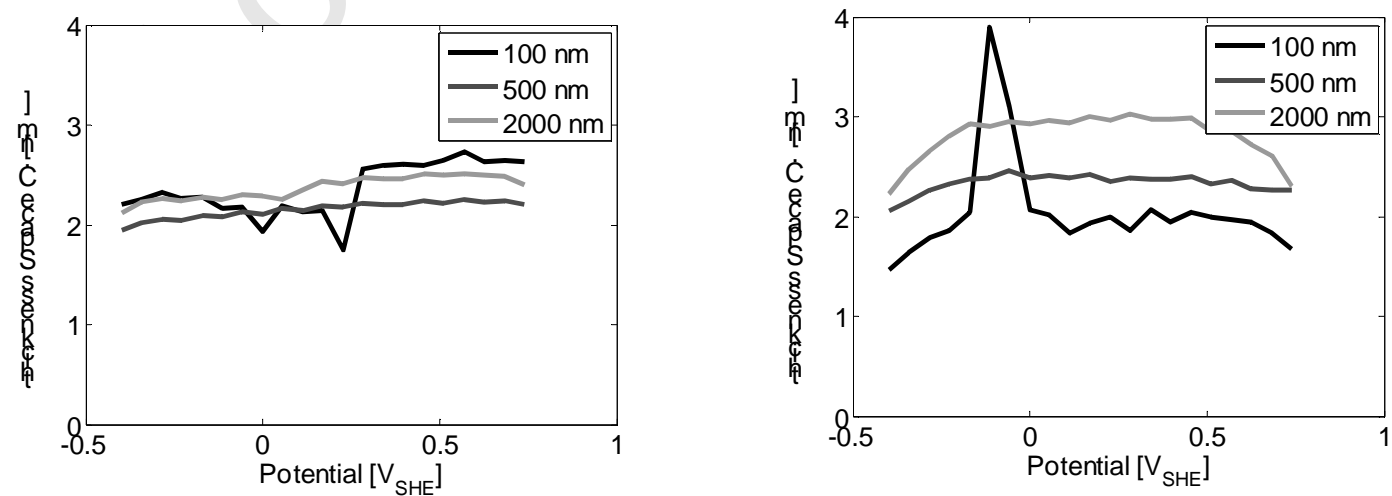

Figure 14. Calculated space charge layer, A) in dark B) under UV illumination 


\section{Conclusions}

1. The magnetron-sputtered $\mathrm{TiO}_{2}$ coatings on aluminium alloy 1050 showed columnar growth of the coating with crystallite size increasing with increase in thickness of the coating. The results also showed a quasi-linear dependency between the crystallites in-plane size, thickness, and increase in surface area with respect to the synthesis time.

2. The refractive index increased linearly with the coating thickness, demonstrating increased density with coating thickness.

3. The methylene blue decomposition test showed an increase in photocatalytic activity with increased coating thickness, which was greater for the thickness range of $100 \mathrm{~nm}$ and $500 \mathrm{~nm}$ compared to the increase between $500 \mathrm{~nm}$ and $2 \mu \mathrm{m}$.

4. The photo-electrochemical test using zero resistance ammetry method showed an increase in photocurrent under UV illumination, with the magnitude of the current increasing with increased thickness of the coating. Similar to the results from the decomposition studies, the difference in photocurrent was higher for coating thickness between $100 \mathrm{~nm}$ and $500 \mathrm{~nm}$, while the difference was negligible between $500 \mathrm{~nm}$ and $2 \mu \mathrm{m}$ thick coatings.

5. The impedance measurements showed a decrease in reaction resistance with coating thickness, indicating more photocatalytic activity for thicker samples. The difference is more obvious in terms of the reaction resistance between the 100 and $500 \mathrm{~nm}$ coatings than between the $500 \mathrm{~nm}$ and $2 \mu \mathrm{m}$ coatings.

6. The space charge capacitance of the coating increased linearly with increased thickness when there was no UV exposure. During UV-illumination the capacitance changed only slightly compared with capacitance in the dark for a given coating thickness. 


\section{Acknowledgements}

The authors would like to thank Juliano Soyama for help with the methylene blue testing and Torben Jacobsen for assistance with the impedance work. Authors would like to acknowledge funding from the Danish Advanced Technology Foundation AMAS project and SETNanoMetro, EU Project. R. Shabadi would like to thank BQR-3b 2014-Univ Lille1 for the financial support for this collaboration.. ACG acknowledges Romanian Ministry of Education - PN-II-RU-TE-2011-3-0016 Project - for financial support.

\section{References}

[1] M. Grätzel, "Photoelectrochemical cells," Nature, vol. 414, pp. 338-344, 2001.

[2] A. Fujishima, T. N. Rao, and D. a. Tryk, "Titanium dioxide photocatalysis," J. Photochem. Photobiol. C Photochem. Rev., vol. 1, no. 1, pp. 1-21, Jun. 2000.

[3] X. Chen and S. S. Mao, "Titanium dioxide nanomaterials: synthesis, properties, modifications, and applications.," Chem. Rev., vol. 107, no. 7, pp. 2891-959, Jul. 2007.

[4] M. M. Ballari, M. Hunger, G. Hüsken, and H. J. H. Brouwers, "NOx photocatalytic degradation employing concrete pavement containing titanium dioxide," Appl. Catal. B Environ., vol. 95, no. 3-4, pp. 245-254, Apr. 2010.

[5] J. Gamage and Z. Zhang, "Applications of Photocatalytic Disinfection," Int. J. Photoenergy, vol. 2010, pp. 1-11, 2010.

[6] A. Fujishima, X. Zhang, and D. A. Tryk, "TiO2 photocatalysis and related surface phenomena," Surf. Sci. Rep., vol. 63, no. 12, pp. 515-582, Dec. 2008.

[7] O. Carp, "Photoinduced reactivity of titanium dioxide," Prog. Solid State Chem., vol. 32, no. 1-2, pp. 33-177, 2004.

[8] I. P. Parkin and R. G. Palgrave, "Self-cleaning coatings," J. Mater. Chem., vol. 15, no. 17, p. $1689,2005$.

[9] V. Augugliaro, V. Loddo, M. Pagliaro, G. Palmisano, and L. Palmisano, Clean by Light Irradiation: Practical Applications of Supported TiO2. Cambridge (UK): RSC Publishing, 2010, pp. 2-5.

[10] A. Selloni, “Anatase shows its reactive side," Water, vol. 7, no. August, pp. 613-615, 2008.

[11] X.-Q. Gong and A. Selloni, "Reactivity of anatase $\mathrm{TiO}(2)$ nanoparticles: the role of the minority (001) surface.," J. Phys. Chem. B, vol. 109, no. 42, pp. 19560-2, Oct. 2005.

[12] H. G. Yang, C. H. Sun, S. Z. Qiao, J. Zou, G. Liu, S. C. Smith, H. M. Cheng, and G. Q. $\mathrm{Lu}$, "Anatase $\mathrm{TiO} 2$ single crystals with a large percentage of reactive facets.," Nature, vol. 453, no. 7195, pp. 638-41, May 2008. 
[13] K. Wilke, "The influence of transition metal doping on the physical and photocatalytic properties of titania," J. Photochem. Photobiol. A Chem., vol. 121, no. 1, pp. 49-53, Feb. 1999.

[14] T. Umebayashi, "Analysis of electronic structures of 3d transition metal-doped TiO2 based on band calculations," J. Phys. Chem. Solids, vol. 63, no. 10, pp. 1909-1920, Oct. 2002.

[15] U. Diebold, “The surface science of titanium dioxide," Surf. Sci. Rep., vol. 48, no. 5-8, pp. 53-229, Jan. 2003.

[16] S. Daviðsdóttir, S. Canulescu, K. Dirscherl, J. Schou, and R. Ambat, "Investigation of photocatalytic activity of titanium dioxide deposited on metallic substrates by DC magnetron sputtering," Surf. Coatings Technol., vol. 216, pp. 35-45, Nov. 2013.

[17] S. Daviðsdóttir, K. Dirscherl, R. Shabadi, S. Canulescu, and R. Ambat, "Nanoscale surface potential imaging of the photocatalytic TiO2 films on aluminum," RSC Adv., vol. 3, pp. 23296-23302, 2013.

[18] K. Jung, "Anatase-phase titania: preparation by embedding silica and photocatalytic activity for the decomposition of trichloroethylene," J. Photochem. Photobiol. A Chem., vol. 127, no. 1-3, pp. 117-122, Oct. 1999.

[19] Y.-J. Cheng and J. S. Gutmann, "Morphology phase diagram of ultrathin anatase TiO2 films templated by a single PS-b-PEO block copolymer.," J. Am. Chem. Soc., vol. 128, no. 14, pp. 4658-74, Apr. 2006.

[20] M. G. Nielsen, S.-I. In, P. C. K. Vesborg, T. Pedersen, K. P. Almtoft, I. H. Andersen, O. Hansen, and I. Chorkendorff, "A generic model for photocatalytic activity as a function of catalyst thickness," J. Catal., vol. 289, pp. 62-72, May 2012.

[21] C. Giolli, G. Rizzi, A. Scrivani, R. Ferpozzi, S. Troglio, M. M. Miranda, A. Tolstoguzov, U. Bardi, F. Borgioli, A. Fossati, A. Credi, A. Di Fabio, S. Parmeggiani, A. Zoppi, A. Scrivani, R. Ferpozzi, M. M. Miranda, Ad. Fabio, S. Parmeggiani, and A. Zoopi, "Development and characterization of TiO2 coatings prepared by electric arcphysical vapour deposition system," Surf. Eng., pp. 27-36, 2008.

[22] A. C. Galca, G. E. Stan, L. M. Trinca, C. C. Negrila, and L. C. Nistor, "Structural and optical properties of c-axis oriented aluminum nitride thin films prepared at low temperature by reactive radio-frequency magnetron sputtering," Thin Solid Films, vol. 524, pp. 328-333, Dec. 2012.

[23] K. Y. Jung, S. Bin Park, and S.-K. Ihm, "Linear relationship between the crystallite size and the photoactivity of non-porous titania ranging from nanometer to micrometer size," Appl. Catal. A Gen., vol. 224, no. 1-2, pp. 229-237, Jan. 2002.

[24] D. Norm, "DIN 52980:2008-10: Photokatalytische Aktivität von OberflächenBestimmung der photokatalytischen Aktivität durch Abbau von Methylenblau," 2008.

[25] A. Wold, "Photocatalytic properties of titanium dioxide (TiO2)," Chem. Mater., vol. 5, no. 3, pp. 280-283, Mar. 1993. 
[26] R. Messier, "Revised structure zone model for thin film physical structure," J. Vac. Sci. Technol. A Vacuum, Surfaces, Film., vol. 2, no. 2, p. 500, 1984.

[27] O. Kluth, G. Schöpe, J. Hüpkes, C. Agashe, J. Müller, and B. Rech, "Modified Thornton model for magnetron sputtered zinc oxide: film structure and etching behaviour," Thin Solid Films, vol. 442, no. 1-2, pp. 80-85, Oct. 2003.

[28] J. A. Thornton, "High rate thick film," Annu. Rev. Mater. Sci., vol. 7, pp. 239-260, 1977.

[29] A. B. Rodriguez-Navarro, "Model of texture development in polycrystalline films growing on amorphous substrates with different topographies," Thin Solid Films, vol. 389, no. 1-2, pp. 288-295, Jun. 2001.

[30] A. C. Galca, V. Stancu, M. a. Husanu, C. Dragoi, N. G. Gheorghe, L. Trupina, M. Enculescu, and E. Vasile, "Substrate-target distance dependence of structural and optical properties in case of $\mathrm{Pb}(\mathrm{Zr}, \mathrm{Ti}) \mathrm{O} 3$ films obtained by pulsed laser deposition," Appl. Surf. Sci., vol. 257, no. 14, pp. 5938-5943, May 2011.

[31] S. Tanemura, L. Miao, P. Jin, K. Kaneko, a. Terai, and N. Nabatova-Gabain, "Optical properties of polycrystalline and epitaxial anatase and rutile $\mathrm{TiO} 2$ thin films by rf magnetron sputtering," Appl. Surf. Sci., vol. 212-213, pp. 654-660, May 2003.

[32] H. K. Pulker and S. S. Schlichtherle, "Density Related Properties of Metal Oxide Films," vol. 5250, pp. 1-11, Feb. 2004.

[33] D. M. Mattox, Handbook of Physical Vapor Deposition (PVD) Processing, Second edi. Elsevier, 2010, pp. 333-398.

[34] G. Abadias, W. P. Leroy, S. Mahieu, and D. Depla, "Influence of particle and energy flux on stress and texture development in magnetron sputtered TiN films," J. Phys. D. Appl. Phys., vol. 46, no. 5, p. 055301, Feb. 2013.

[35] A. Le Febvrier, A. C. Galca, Y. Corredores, S. De, D. Rennes, U. De Rennes, and I. U. T. De Saint-brieuc, "Structural, Optical, and Dielectric Properties of Bi 1.5 -," Appl. Mater. interfaces, vol. 4, pp. 5227-5233, 2012.

[36] S.-C. Jung, S.-J. Kim, N. Imaishi, and Y.-I. Cho, "Effect of TiO2 thin film thickness and specific surface area by low-pressure metal-organic chemical vapor deposition on photocatalytic activities," Appl. Catal. B Environ., vol. 55, no. 4, pp. 253-257, Feb. 2005.

[37] M. Heikkilä, E. Puukilainen, M. Ritala, and M. Leskelä, "Effect of thickness of ALD grown TiO2 films on photoelectrocatalysis," J. Photochem. Photobiol. A Chem., vol. 204, no. 2-3, pp. 200-208, May 2009.

[38] D. . Blackwood, "Influence of the space-charge region on electrochemical impedance measurements on passive oxide films on titanium," Electrochim. Acta, vol. 46, no. 4, pp. 563-569, Dec. 2000. 
[39] K. Hashimoto, H. Irie, and A. Fujishima, "TiO 2 Photocatalysis: A Historical Overview and Future Prospects," Jpn. J. Appl. Phys., vol. 44, no. No. 12, pp. 8269-8285, Dec. 2005.

[40] C. A. I. Tiejun, L. Yuchao, P. Zhenshan, L. Yunfei, W. E. I. Zongyuan, and D. Qian, "Photocatalytic performance of $\mathrm{TiO} 2$ catalysts modified by $\mathrm{H} 3 \mathrm{PW} 12 \mathrm{O} 40, \mathrm{ZrO} 2$ and CeO2," J. en, vol. 21, pp. 997-1004, 2008. 
7. The magnetron-sputtered $\mathrm{TiO}_{2}$ coatings on aluminium alloy 1050 showed columnar growth of the coating with crystallite size increasing with increase in thickness of the coating. The results also showed a quasi-linear dependency between the crystallites in-plane size, thickness, and increase in surface area with respect to the synthesis time.

8. The refractive index increased linearly with the coating thickness, demonstrating increased density with coating thickness.

9. The methylene blue decomposition test showed an increase in photocatalytic activity with increased coating thickness, which was greater for the thickness range of $100 \mathrm{~nm}$ and $500 \mathrm{~nm}$ compared to the increase between $500 \mathrm{~nm}$ and $2 \mu \mathrm{m}$.

10. The photo-electrochemical test using zero resistance ammetry method showed an increase in photocurrent under UV illumination, with the magnitude of the current increasing with increased thickness of the coating. Similar to the results from the decomposition studies, the difference in photocurrent was higher for coating thickness between $100 \mathrm{~nm}$ and $500 \mathrm{~nm}$, while the difference was negligible between $500 \mathrm{~nm}$ and $2 \mu \mathrm{m}$ thick coatings.

11. The impedance measurements showed a decrease in reaction resistance with coating thickness, indicating more photocatalytic activity for thicker samples. The difference is more obvious in terms of the reaction resistance between the 100 and $500 \mathrm{~nm}$ coatings than between the $500 \mathrm{~nm}$ and $2 \mu \mathrm{m}$ coatings.

12. The space charge capacitance of the coating increased linearly with increased thickness when there was no UV exposure. During UV-illumination the capacitance changed only slightly compared with capacitance in the dark for a given coating thickness. 